\title{
NOTAS SOBRE LA CRISIS Y LOS PARTIDOS POLITICOS EN BRASIL
}

\author{
Ariel Jerez Novara (*)
}

\section{BREVE APROXIMACION A UNA CRISIS DE ESTADO.}

La crisis vivida por la sociedad brasileña simultanea una vertiente económica, derivada de lo que algunos autores han llamado el fín del Ciclo Estatal de Desarrollo y que implica la necesidad de transformaciones estructurales para lograr una reinserción de su economía en un mercado mundial transnacionalizado, conditio sine qua non para articular un nuevo proyecto de nación (1); con una crisis institucional derivada de la forma que adquiere la construcción del Estado en Brasil, cómo afecta en particular a la representación política, que en la actualidad se ve agravada por la inadecuación de los viejos actores socio-políticos protagonistas del anterior ciclo de desarrollo, cuya actuación en el marco de las instituciones políticas es totalmente disfuncional para llevar a cabo el concenso social ineludible para articular políticamente las conflictivas y necesarias reformas estruturales para salir de la crisis.

En esta situación se encuentra sumergido un sistema político en el que viejos actores aprenden nuevos papeles a representar, mientras otros defienden con fuerza sus papeles mostrando su intención de no aprender; nuevos actores piden más y mejores papeles, a la vez que voces fuera del escenario muestran su voluntad de ser actores.

Para entender la lógica de un sistema partidario dinamizado por todas estas fuerzas es necesario exponer someramente las características del funcionamiento del Estado brasileño. El más moderno del tercer mundo en los 60 , que coloca su economía entre las diez más industrializadas del mundo, tiene en su origen un grave handicap (2): es construido por medio de amplias alianzas de unas élites económicas regionales que intentan controlar un vasto y heterogeneo territorio, y que consolidan su poder político por medio de una repartición patrimonial del Estado. Dinámica de alianzas que se complejizará en términos de sujetos sociales implicados y mecanismos de dominación- subordinación en ese conjunto de rasgos que configuran el modelo populista, implantado por G. Vargas en la decada del 30, y que será "modernizado" y sofisticado por las particulares caracteristicas del proyecto autoritario instaurado en el 64.

El resultado de ese proceso histórico es, en grandes rasgos, un estado hipertrofiado por el atendimiento de las demandas de los viejos actores socio-políticos del pacto corporativo populista, y a la vez privatizado por formas arcaicas de hacer política (patrimonialismo, corrupción y clientelísmo) que desvirtuan la noción de ciudadania, que se percibe como regulada/otorgada, cuestión que marcará la cultura política e, a nivel más amplio, la propia concepción de lo público como espacio progresivamente desvinculado de la sociedad civil. No en vano, la opinión pública enfatiza los elementos morales y éticos de la crisis.

En la actulidad este Estado, que por esas causas internas y otras externas de orden económico-financiero ya no tiene capacidad de reproducirse, se ve imposibilitado para responder a las demandas de los actores excluidos de dicho pacto. Estos empiezan a tener voz, paulatinamente más grave y adulta al conformarse en sus luchas sociales como movimientos a ser escuchados por las fuerzas políticas, en la medida en que avanza el proceso de redemocratización iniciado en 1974, a partir de una "descomprensión lenta, gradual y segura" que permitirá elegir presidente directamente recien a finales de 1989 . Un proceso político que ha sido caracterizado como transición pactada por arriba, "transada", que ha posibilitado que las élites políticas se mantengan casi inalteradas en la nueva fase democrática.

\section{UN ORDEN POLITICO QUE NECESITA PARTIDOS DEBILES.}

En la medida en que todas las instituciones son una cristalización histórica de determinada práctica colectiva, es necesario entender que el proceso de construcción del

(*) Investigador del Departamento de Ciencia Política de la Facultad de Ciencias Políticas y Sociología de la UCM; recientemente investigador invitado en el Centro de Estudios de Cultura Contemporanea (CEDEC) y en el Centro Brasilerio de Analise e Planejeamento (CEBRAP) de Sao Paulo.

(1) Entendiendo proyecto de nación en su simple asepción de hacer posible la existencia de una sociedad política y territorialmente integrada a lo largo del tiempo, cuestión cada vez cuestionada por la existencia de crecientes areas desintegradas y/o anómicas de la sociedad cada vez más disfuncionales en términos de legalidad y legitimidad para el sistema. En este sentido, ver los diversos trabajos de H.Jaguaribe (et alli) elaborada desde el Insituto de Estudos Políticos e Sociais. Para un análisis sobre el concepto de nación en Brasil ver Ianni,O.: "La nación brasileña", $R E P, \mathrm{n}^{\circ}$ 74, Madrid, 1991.

(2) No solo en relación a las características de construción del Estado en Europa o en EE.UU, sino en relación a sus vecinos latinoamericanos: la invasión napoleónica de Portugal, y el consiguiente traslado de la Casa Real a Brasil, configuran un peculiar y continuista proceso de independencia del Imperio a la $1^{\mathrm{a}}$ República (1822-1889). 
estado en Brasil se caracteriza por la existencia de un poder central que impide, en un primer momento por medios represivos y posteriormente combinados con medios legales, el surgimiento de partidos nacionales que pudiesen cuestionarlo (3). Estos últimos a partir del la posguerra , y sobretodo en el periodo autoritario se convierten en una verdadera obra de "ingenieria política" a los intereses del régimen.

Por cuestiones de espacio, intentaremos aproximarnos a la compleja dinámica de las instituciones políticas limitandonos a señalar e ilustrar algunos de sus rasgos más pervertidos en relación a como los partidos políticos ven dificultada su labor destinada a fortalecerse como instituciones políticas, en términos de su implantación a nivel nacional, de la definición de identidad partidaria en el seno de la sociedad, su cohesión interna, rasgos indispensables para que cumplan un papel funcional en el proceso de consolidación democrática. En este sentido intentaremos hacer un recorrido por los elementos conflictuantes del sistema político brasileño.

En lo que respecta al sistema partidario, con la excepción del Partido dos Trabalhadores (PT) y el Partido da Socialdemocracia Brasileira (PSDB), estos no cumplen los requisitos mínimos de modernidad en relación a la naturaleza de la organización interna, personalidades que los integran y su comportamiento público, o a la selección de candidatos según criterios de competencia. Se observa, en última instancia, una pérdida de responsabilidad de los partidos políticos frente a la sociedad en el sentido en el que no son portadores de propuestas públicas ni representantes de amplios sectores sociales, donde la escasa fidelidad partidaria y sus débiles compromisos ideológicos anulan la imagen de autenticidad necesaria para orientar a la ciudadania en su elección política (4). Sobre las actuales transformaciones del sistema partidario volveremos más tarde.

En relación a la forma de gobierno, el presidencialismo “imperial" brasileño, a pesar de haber sido atenuado en la Constitución del 88 , sige manteniendo una considerable capacidad de veto sobre las iniciativas legislativas del Congreso, así como la capacidad de gobernar através de "medidas provisorias" a retificar por las Camaras en treinta dias, plazo suficiente para "articular" los apoyos necesarios. Esto se debe a que la organización federal del Brasil tiene peso en el funcionamiento de las Cámaras, en la medida en que la estructura tributaria de la Unión obliga a la negociación en lo que respecta a las transferencias de recursos hacia los Estados, llevandose a cabo directamente entre el Presidente de la República y los gobernadores.
Estos tienen capacidad de formar bloques suprapartidarios en el Congreso de cada estado para negociar el apoyo a las iniciativas presidenciales, en la medida en que vuelven a negociarse transferencias de recursos o apoyos en las Cámaras de sus respectivos estados o municipalidades importantes con esos mismos partidos. "Dando es que se recibe" es una de las máximas que domina la vida legislativa brasileña, desde la Cámara Municipal en que se producen estas negociaciones en escala micro: del vereador (concejal), que hace de mediador ante el ejecutivo, con los "articuladores sociales" de las clientelas, que pueden ser desde lideres de movimientos populares o presidentes de asosiaciones de comerciantes e incluso, como ya se han dado casos, lideres de los complejos entramados sociales que se desarrollan en torno a las rentas del narcotráfico.

Un sistema electoral que combina elecciones mayoritarias con segunda vuelta para Presidente, gobernadores y alcaldes de ciudades de más de 200.000 habitantes, con mayoritarias simples para senadores y el resto de alcaldes; y proporcionales para diputados federales y estaduales, haciendo algunas de ellas simultaneas, no hace más que dificultar a la ciudadania (con bajos niveles de escolaridad) la percepción de la lógica institucional del proceso político, alejandolo del mismo con consecuencias nefastas en la valorización y apego a una institucionalidad democrática heredera de corrupción y clientelismo, que ahora se hace evidente en cualquier medio de comunicación, y que sin embargo continua sin solucionarse 5 .

Por su parte las elecciones proporcionales, de lista abierta, donde el elector vota en un candidato y no en un partido, hacen que la competencia intrapartidaria sea más fuerte que la interpartidaria, al incentivar el individualismo en la busqueda de recursos, ya que los políticos dependen de sus propias iniciativas y esfuerzos para llevar a cabo su candidatura. Esto se combina con una legislación que permite una total intromisión del poder económico en las campañas electorales lo que tiene serias consecuencias en términos de corrupción y nepotismo.

Graves son las consecuencias de este sistema electoral en términos de la representación política, cuestión agravada a partir de la Constitución del 88. Este garantiza una sobrerrepresentación de los estados del Norte-Nordeste, ligados a las prácticas más arcaicas de los "reductos electorales del coronelismo" y a los intereses económicos vinculados al latifundio. La máxima distorsión es entre el estado de Rondonia y Sao Paulo, donde sus diputados federales representan a 9.100 y 308.400 electores respectivamente (6).

(3) A lo largo de su historia como nación independiente, Brasil muestra 7 configuraciones partidarias distintas, donde las discontinuidades evidencian casuismos institucionales. Ver Lamounier,B y Menegello,R: "Partidos politicos e Consolidaçao democrática: o caso brasileiro". Documento de trabajo IDESP. Sao Paulo 1986.

(4) Ver Jaguaribe, H.: "Sociedade, Estado e partidos na atulidade brasileira" en A crise brasileira e a modernizaçao da sociedade. Ed. J. Olympio, Rio de Janeiro, 1990.

(5) No podemos entrar en un análisis de la cultura política, pero contra algunos argumentos que han intentado utilizarla como factor explicativo de la desarticulación en el funcionamiento de las instituciones democráticas, pensamos que, y en esta coyuntura más que nunca, no es justo históricamente, ni beneficioso intelectual ni políticamente, otorgar igual responsabilidad al conjunto de la sociedad, y no distinguir los sujetos socio-políticos que su acción ha sido negativa o positiva para el proceso de integración social implicito en el proceso de redemocratización.

(6) Distorsión de 1 a 32, grotesca comparada con la producida por el sistema electoral español que en las legislativas generales tiene su máxima distorsión, de 1 a 4, entre Melilla y Madrid. En el anexo I aparece dicha desproporcinalidad antes y despues de la constitución del 88. 
A su vez una ley partidaria totalmente permisiva, sin clausulas de exclusión ni mecanismos que garanticen la fidelidad partidaria ni controlen el transfugismo político, hacen que en las elecciones de octubre del 90 la Cámara acogiese a diputados de 19 partidos y que, en media, hayan pertenecido cada uno de ellos a 2,6 partidos políticos (7).

Analizar, ni siquiera brevemente, los agentes sociales e institucionales que tienen influencia en el sistema político no es posible en el espacio de este trabajo, pero vale la pena mencionar que la gran mayoria de ellos tiene una actuación visiblemente corporativa, a exepción de amplios sectores sindicales vinculados a la Central Unica dos Trabalhadores (CUT) (ver anexo II:PT) y empresariales que constituyen la organización Pensamento Nacional das Bases Empresariais (PNBE) (8), que intentan articular las bases de un mínimo pacto social. Labor que se ve recompensada con un creciente protagonismo en la vida política y la opinión pública (9).

Todos estos elementos posibilitan y refuerzan una lógica individualista en la actuación de los políticos, y tienen serias repercusiones en el funcionamiento de los partidos políticos y la profesionalización de la política. La opinión pública cuestiona su irresponsabilidad, en tanto carencia de una actuación programática, que se evidencia sobre todo en los periodos electorales cuando se activan todos sus mecanismos clientelísticos (10). Estos rasgos son reforzados por la lógica: en el momento de la campaña, al requerir una mayoría electoral absoluta el partido personaliza su actividad electoral en la figura del candidato, lo que diluye las fronteras ideológicas entre las diferentes opciones; y como acción de gobierno convierte su actividad en un juego de suma cero, donde un adversario gana y pasa a ser el único que tiene voz, mientras el otro es marginado, aniquilandose la posibilidad del dialogo político entre las diferentes posturas. Una de las cuestiones más dolorosas para la institucionalidad democrática es la posición que le queda al Congreso en esta situación, que es percibido como instancia sin sentido político, donde los políticos "arreglan sus asuntos".

\section{ELECCIONES Y SISTEMA DE PARTIDOS EN RECOMPOSICION.}

Es sumamente complicado hacer un análisis electoral global en la medida en que cada tipo de elección tiene una lógica propia, y como ha ocurrido en muchos de los análisis realizados en medios periodísticos pueden llegarse a conclusiones erroneas (11). Creo que la máxima expresión de que el sistema de partidos en Brasil está en recomposición fueron las elecciones presidenciales del 89 , primeras elecciones directas en 28 años, donde hubo un grado de movilización política y social comparable al de campaña "Direitas ja!" en 1984. No es casual que los dos partidos que alcanzan el segundo turno sean el PRN y el PT, un "outsider" de la política nacional y un partido que podriamos llamar radical con una bancada de, en ese momento, 16 diputados.

No pudiendo entrar en un análisis pormenorizado de la campaña presidencial, es necesario tener en cuenta que el PRN y su candidato, el actual presidente Fernando Collor de Mello, es producto de un trabajo de marketing político, creado pocos meses antes de las elecciones y que centrado en una imagen de un joven agraciado, deportista y decidido con su discurso lapidario hacía el anterior jefe de gobierno, J. Sarney, y hacía los políticos en general, lograba hacer creible ante grandes segmentos del electorado su propuesta de renovación política (12). Por su parte, el PT sí es realmente una novedad en el cuadro partidario brasileño, en tanto propuesta, renovación de élites, acción de gobierno y canal de demandas de nuevos actores sociales (13), lo que polarizó idelógicamente una dura y tergiversada campaña electoral.

Las elecciones legislativas del 90, aunque dentro de una continuidad relativa, tambien evidencian la recomposición. Se puede observar cómo en grandes rasgos la derecha crece moderadamente en las últimas legislativas, manteniendo sus reductos electorales norteños-nordestinos, aunque con diferencias entre partidos. El PFL como participe del

(7) Ejemplo ilustrativo es el PRN (en el anexo II presentamos un breve mapeamiento de los partidos políticos), actual partido de gobierno, que antes de presentarse a elección alguna contaba con 20 diputados en la Cámara, lo que le posibilitó hacer uso de los espacios gratuitos de televisión durante la campaña presidencial.

(8) En que estos momentos se encuentra disputado, con posibilidades de éxito, la presidencia de la Federación de Industrias del Estado de Sao Paulo (FIESP), la más poderosa organización patronal del país.

(9) Iniciativas como Opción Brasil, la participación en el Foro da Cidade de Sao Paulo, o Forum Paulista de Desenvolvimiento, intentan articular por medio de la participación de entidades civiles concensos mínimos sobre reformas puntuales, o el control sobre la asignación y gestión de recursos en el funcionamiento diario de la administración.

(10) Más allá de los habituales, sorprende como se hace un uso demagógico de obras públicas, con evidentes irregularidades "improbables", dado la obstaculización política sistemática en las "comisiones de inquerito". La resignada expresión popular "roba pero hace" le ha dado pie al ex-gobernador paulista O.Quercia, virtual candidato presidencial por el PMDB, para considerar públicamente irresponsable a un gobernante que al terminar su mandato no tiene déficit presupuestario. Al mes "prestaría "su bancada, junto a otros gobernadores, para acelerar el proceso de privatizaciones del Presidente Collor a cambio de una condonación de las deudas estatales con los fondos federales.

(11) Uno de los mayores fue la tan difundida e intencionada idea del descalabro de la izquierda, del PT en particular, al comparar las elecciones legislativas del 90 con las presidenciales del 89. Ver Dillon Soares,G.A. y D'Araujo, M.C.: "Los mitos de la prensa y los votos en las elecciones de 1990", en REP, N74, Madrid, 1991.

(12) A pesar de tener un pasado político ligado a ARENA, Collor logró através de un eleborado trabajo de imagen y un discurso populista conectar con las capas menos escolarizadas y más marginadas del sistema político, "los descamisados". Posteriormente, en un segundo turno polarizado en torno al "ogro comunista" que los medios de comunicación hicieron de Lula, contó con el apoyo decidido de toda la derecha tradicional, e incluso lideres de centro izquierda. Ver Singer, A.: "Collor na periferia: a volta por cima do populismo?" en B Lamounier De Geisel a Collor. Ed. Sumaré, Sao Paulo, 1991.

(13) Propuesta derivada de un proceso amplio y complejo de configuración de una fuerza netamente popular, única como real opción de gobierno en el marco latinoamericano, que requiere un análisis pormenorizado que aquí no podemos abordar. Quiza el mejor trabajo hasta el momento sea el de Keck, M.: PT: A lógica da diferença. Ed. Atica, Sao Paulo, 1991. 
gobierno Sarney ve reducida su bancada en el 90 en relación a la del 86 (ver anexo IV).

Por su parte, la izquierda viene teniendo un crecimiento proporcionalmente mayor (el PT dobla su bancada de 8 diputados en el 82 en el 86 y nuevamente en el 90; el PDT solo lo haría en el 90 en relación a la del 86), más orgánico en la medida va acompañado, sobre todo en el caso del PT, en un aumento de militancia y nucleos en zonas rurales donde antes no existía, dado el crecimiento que viene teniendo el sindicalismo rural vinculado a su central sindical, la CUT.

Quien realmente pierde caudal electoral es el espacio de centro del espectro político, ocupado en la actual coyuntura por el PMDB y PSDB, sustento básico del gobierno Sarney. Paralelamente se observa un crecimiento de una abstención difícil de analizar en la medida en que diversos estudios muestran las serias dificultades que tiene el electorado brasileño para votar en unas elecciones como las del 90 , donde se simultaneaban proporcionales y mayoritarias para dos cargos distintos cada una de ellas, a la vez que se observa un creciente "desencanto" con la política y los políticos (14).

\section{A MODO DE CONCLUSION.}

A pesar de la complejidad de la dinámica partidaria derivada de una institucionalidad política, cuyos puntos más conflictuantes hemos intentado esbozar,podemos afirmar que si el sistema de partidos no se encuentra en crisis, en el sentido de que podamos percibir el movimiento producido por el surgimiento de nuevas fuerzas u opciones que descalabran el orden vigente, sí lo esta un sistema político "oligárquico-privatista", que viene siendo cuestionado cada vez más eficientemente por fuerzas débiles todavía electoralmente, por la opinión pública que denuncia, muchas veces de forma contradictoria, una crisis moral de la vida política que lleva el país a la deriva.

Desde esta perspectiva, el sistema partidario esta en recomposición en su dimensión de la correlación de fuerzas, en la medida en que la izquierda crece, las posturas "modernizantes" de diversos agentes de la sociedad civil de gran incidencia en la opinión pública presiona a los partidos tradicionales en dirección de la renovación de liderazgos y prácticas políticas. De forma gradual e irrevocable, se va articulando una fuerza demecrático -republicana, que tiene como objetivo la progresiva ampliación de la ciudadania a los sectores marginados de la población, que pueden diferir en cómo conseguirlo, pero en un concenso total en torno al marco de la institucionalidad democrática que tiene que acompañar a dicho procesos de reformas.

Fuerza de renovación que viene gestandose hace decadas, cuyo punto de inflexión fué el proceso huelguistico de los años 78-79 del que surguiría el PT. Acontecimiento que marca hito en la medida en que se configuró, por primera vez en la historia del Brasil, una representación políticamente autonoma de las clases trabajadoras, y por extensión subalternas, cuya voluntad transformadora no puede ser ignorada en ninguna de las dimensiones de la vida política nacional. Un revulsivo en la sociedad brasileña, y sobre todo en el estado de Sao Paulo donde el poder municipal le ha dado la posibilidad de mostrar su voluntad transformadora, que ha obligado a todas las demás fuerzas políticas y actores sociales a repensar y modificar sus estrategias, y trabajar sobre los puntos de convergencia para lograr un pacto social.

Como hemos intentado exponer anteriormente, diversos mecanismos institucionales logran una real subrrepresentación de los correlatos partidistas con los que esta fuerza cuenta en la Cámara Federal (15).

La propia dinámica competitiva entre estos partidos, por capitalizar el movimiento visible a nivel de iniciativas de las organizaciones de la sociedad civil, dificulta la percepción de las crecientes convergencias que se dan entre ellos. Toda esta fuerza renovadora que busca un pacto social integrador, todavía no tiene propiamente sujeto histórico por el que expresarse, en la medida en que son sujetos diversos, originados en problemáticas sociales distintas. En este punto es crucial el referendúm, previsto en la Nueva Constitución para el 7 de septiembre de 1993, en el que se optará por una forma de gobierno parlamentarista ó presidencialista (cuyas características determinará el Congreso) (16). El parlamentarismo sería una opción que coadyuvaría significativamente en la convergencia de estas fuerzas en un programa mínimo, que pueda ser empezado a ser defendido desde la sociedad como un proyecto para el Brasil. Tanto partidos como congresistas de derecha e izquierda, mayoritariamente, han ido evolucionando hacia posiciones parlamentaristas, aunque es una cuestión sumamente complicada en relación a una cultura política impregnada de paternalismo, que otorga ciertas características redentoras a la figura presidencial. El posicionamiento del actual presidente, por ahora bastante ecléctico en esta cuestión, y de los grandes medios de comunicación serán decisivos en esta disputa.

Esta dinámica renovadora, por otra parte, viene viendose reforzada por unas nuevas coordenadas internacionales: fín de guerra fría y revalorización democrática que deslegi-

\footnotetext{
14 En el anexo III mostramos la evolución de votos blancos y nulos en las elecciones legislativas. Hay que tener en cuenta que el voto es obligatorio.

15. En el Congreso se ha articulado un bloque de de sustentación del gobierno (PFL,PRN, y PMN), que cuenta con la "fuerza auxiliar" del bloque independiente (PTB, PDS, PL y PDC) y la derecha del PMDB, y coyunturalmente con diputados del PSDB, para llevar a cabo las votaciones duras. A despecho de los intentos de agrupamiento de la oposición que ha ido acercando sectores del PMDB, a la alianza que vienen manteniendo el PSDB y el PT en sus iniciativas legislativas. El PDT intenta caminar en dirección del PC do B y a los rebeldes de los tres partidos anteriores, aglutinados por su preferencia preesidencialista. En el anexo IV vemos la evolución en la composición del Congreso.

16 En el anexo $\mathrm{V}$ podemos ver las preferencias entre los congresistas por partido y por opción. Como se puede comprobar tambien se opta por un régimen monárquico ó repúblicano. Esta clausula aparentemente un tanto lunática, fue introducida en el periodo constituyente gracias a los esfuerzos de un único parlamentario, y en principio no tiene viabilidad alguna. No en tanto, para sendas opciones los los lideres de opinión jugarán un papel decisivo.
} 
tima la vía armada para acceder al poder; observación de la inestabilidad política de paises vecinos producto de recetarios neoliberales marginan a sectores crecientes de la población; aprendizaje de las experiencias del este de la necesidad de la fuerza política emanada de la movilización social para emprender reformas.

Las elecciones municipales de noviembre de este año son el primer examen de importancia para medir el grado de convergencia de las distintas fuerzas partidarias que se encuentran comprometidas con este movimiento. Partidos políticos en la oposición todos ellos, que tienen que vencer la inercia de una dinámica totalmente contraria a este proceso de convergencia, pero inevitable si no se quiere que el pais siga agravando su crisis y las consecuencias anómicas en lo social, que ya empiezan a sentirse en la vida cotidiana de los más acomodados ciudadanos.

\section{ANEXO I:}

\section{Representación Regional en la Cámara de Diputados}

\begin{tabular}{|l|r|r|r|r|r|r|r|}
\hline \multirow{2}{*}{ REGIONES } & \multicolumn{4}{|c|}{ Bancadas Federales } & \% de la & Numero & Diferencia \\
\cline { 2 - 5 } & \multicolumn{2}{|c|}{1986} & \multicolumn{2}{|c|}{1991} & Población & ideal $(*)$ & $(*)$ \\
\cline { 2 - 4 } & \multicolumn{1}{|c|}{$(\mathrm{N})$} & \multicolumn{1}{|c|}{$\%$} & $(\mathrm{~N})$ & $\%$ & & & \\
\hline Norte & 47 & 9,65 & 65 & 12,92 & 6,55 & 33 & +32 \\
Nordeste & 149 & 30,60 & 151 & 30,00 & 28,50 & 143 & +8 \\
Sudeste & 169 & 34,70 & 169 & 33,60 & 43,63 & 220 & -51 \\
Sur & 82 & 16,84 & 77 & 15,32 & 15,15 & 76 & +1 \\
Centro-Oeste & 40 & 8,21 & 41 & 8,15 & 6,17 & 31 & +10 \\
TOTAL & 487 & 100 & 503 & 100 & 100 & 503 & -- \\
\hline
\end{tabular}

(*) Número ideal si la representación fuese estrictamente proporcional a las poblaciones regionales, y la diferencia, en escaños, en relación a la actual legislatura. La región sudeste, que considera los escaños de Sao Paulo, Minas Gerais, Rio de Janeiro y Espíritu santo, es la más industrializada del país.

\section{ANEXO II:}

\section{Partidos políticos en el Congreso nacional. Mapeamiento}

\section{Partido do Movimento Democrático Brasileiro (PMDB).}

Sucesor del MDB, producto del bipartidismo compulsorio organizado por el régimen militar a partir del Acta Institucional $\mathrm{N}^{\circ} 5$, en 1966. Concebido como partido de oposición que cobijara a las más diversas fuerzas democráticas, se irá fortaleciendo a lo largo de la transición. Con el realineamiento partidario obligado por la Ley de Partidos Políticos de 1979, perderá la mitad de su bancada para el PDS y el Partido Popular, aunque este último sería reincorporado posteriormente. En la elección presidencial indirecta de 1985, en coalición con el PFL, ganarian con la candidatura Tancredo Neves/Sarney, aunque la muerte prematura del primero dejaría el gobierno paulatinamente en manos de sectores vinculados al PFL. Divisiones internas harian que en 1988 se produciese una escisión de la que surgiria el PSDB. Partido de ámbito nacional, de gran heterogeneidad ideológica, que lo vinculan a las formas tradicionales de hacer política, cuenta con ciertos cuadros, más que liderazgos, "modernos" en la zona centro-sur dispuestos a articular un proyecto político con las fuerzas de centro-izquierda.

\section{Partido Democrático Social (PDS).}

En 1980 sucede a la Alianza Renovadora Nacional (ARENA), partido oficialista durante el periodo bipartidario, que controló todos los gobiernos estatales (excepto Rio de Janeiro) y el federal hasta 1979. Sus prácticas fisiologistas y autoritarias, y el el caracter personalista y discurso demagógico de su máximo lider, Paulo Maluf, figura destacada de Arena durante el régimen militar han ido haciendole uno de los representante de la derecha "menos civilizada", no en el sentido de golpista (posibilidad descaratada por todas las fuerzas partidarias en la actual coyuntura), sino por sus planteamientos populistas neoliberales, que camuflan ideas de darwinismo social.

\section{Partido da Frente Liberal (PFL).}

Surge de una escisión del PDS en 1984 por motivos de la elección del candidato para la elección presidencial del 85, dados que varios de sus dirigentes discordaban de la candidatura de Paulo Maluf por medio de una Convención Nacional del partido y pretendian realizar una previa electoral. Conforman la "Alianza Democratica" con el PMDB en el colegio electoral que elegiria al Presidente. Durante el proceso constituyente desempeña un importante papel en la defensa de los intereses moderados y conservadores, al ser la base aglutinadora del "Centrâo", que reunia a los parlamentarios del centro y de la derecha de los distintos partidos. En las presidenciales de 1989, ya directas,cuando su candidato,Aureliano Chaves, evidenciaba su fracaso en la campaña, apoyados por el Presidente J.Sarney lanzarian un nuevo candidato, el empresario Silvio Santos através de un "partido de alquiler", que seria rechazado por la justicia electoral. Con un discurso neoliberal más sofisticado, ha articulado en el Congreso el Bloque de Economía de Mercado, para apoyar el proceso de privatización y destatalización llevado a cabo por el actual gobierno. Sus bases electorales estan principalmente en el Nordeste.

\section{Partido Democrático Trabalhista (PDT).}

Con la amnistia general del 79, Leonel Brizola, lider histórico del laborismo brasileño regresa triunfante, e 
intenta reunir los restos del viejo Partido Trabalhista Brasileño, a otros opsicionistas al régimen militar en el estado de Rio Grande do Sul para las elecciones de 1982. El PMDB se resiste a colocarse bajo el liderazgo de Brizola por lo que se ve obligado a refundar el antiguo PTB. La ex-diputada I. Vargas, sobrina del ex-presidente que le disputa el nombre del partido, que será resuelto por la justicia electoral de forma poco clara, le obligará a aceptar su nuevo nombre. Gobernador de Rio de Janeiro en 1982 y en 1990, tiene sus bases electorales en los estados de Rio de Janeiro y Rio Grande do Sul. Con influencia, decreciente, en ciertos sectores sindicales, el caracter personalista del liderazgo de Brizola ( máximo opositor al parlamentarismo) y el pactismo de su politica como gobernador, por un lado, le rinden fruto dentro de sus "territorios", a la vez que le dificulta articular cualquier propuesta con el resto de la izquierda. Esto no quita que su apoyo al PT fuese el más decidido en el segundo turno de las presidenciales. Uno de los pilares fundamentales de la izquierda brasileñas, aunque mantiene posturas nacionalistas y estatistas un tanto demagógicas, no en tanto es el tercer partido del Congreso.

\section{Partido Trabalhista Brasileño (PTB)}

Creado por G. Vargas en el 45, desaparece en 1965 por el Acta Institucional $\mathrm{N}^{\circ} 2$, volviendo a resucitar en 1980. Siendo disputada sus siglas por L.Brizola, queda comandado por Ivette Vargas. En 1983 se alia en el Congreso con el PDS para dar sustentación al Gobierno del Gral. Figueiredo, recibiendo cargos en el tercer escalon de gobierno.En las elecciones presidenciales del 89 hubo un intento de presentar una candidatura conjunta con el PDT que seria abortada por sectores internos del partido. $\mathrm{Su}$ implantación más fuerte es en la zona norte, aunque tiene reductos electorales en todo el país. Como partido "trabalhista", su originalidad radica en que el $52,63 \%$ de su bancada parlamentaria son liderazgos de la patronal, teniendo un solo sindicalista entre sus representantes.

\section{Partido da Socialdemocracia Brasileira (PSDB).}

Nacido de una escisión de parlamentarios ligados al movimiento de Unidad Progresista a mediados del 88, casi todos del PMDB, comenzó con 70 parlamentarios. Sus estrellas son los senadores Mario Covas,Jose Richa y F.H.Cardoso y el diputado Jose Serra, articuladores de iniciativas diversas con fuerzas de la sociedad civil en la dirección del pacto social para iniciar las reformas del estado. Partido de cuadros, con bases electorales en clases medias y medias-altas urbanas, compuesto básicamente por intelectuales, profesionales liberales y técnicos vinculados al medio gerencial estatal y privado, con gran influencia en la opinión pública, en los medios académicos y empresariales modernos, tiene el handicap de estar desvinculado de los sectores populares y su base electoral reducida a la zona del sudeste y el estado de Ceará (NE). Su propuesta socialdemócrata moderna y moderada le han llevado a seguir una política de centro, "ficar em cima do muro", de dificil intelección en la realidad brasileña. Además de estar articulando trabajos legislativos en el Congreso Nacional, para las municipales del 92 se estan preparando alianzas con el PT para grandes capitales. Disputa la corriente socialdemócrata con el PDT.

\section{Partido Socialista Brasileño. (PSB).}

Surgido en 1947 de diversas corrientes socialistas históricas, no supo ocupar el espacio dejado por la ilegalización del PCB en 1948. Su tamaño es pequeño al ser extinto en 1965, surgiendo nuevamente en 1986. Formó parte del frente Brasil popular en las presidenciales de 1989. Su máximo lider es el diputado M.Arraes, elegido con la mayor votación individual del país.

\section{Partido dos Trabalhadores (PT).}

Articulado en 1979 por los nuevos liderazgos sindicales surgidos en la periferia industrial de Sao Paulo, es creado para ser un partido de la clase trabajadora sin políticos tradicionales. Cuenta con el apoyo total de la Iglesia progresista, intelectuales y de gran influencia en los medios universitarios, su fuerza radica en su estrecha vinculación con los diversos movimientos sociales, tanto urbanos como rurales. Es el único partido moderno, societario y de masas en el sentido duvergeriano, en la medida en que sus concepciones ideológicas configuran sus caracteristicas organizacionales, con una solida estructura de militancia (alrededor de 700.000) y un soporte sindical provisto por la Central Unica dos Trabalhadores (CUT), de 12.000.000 de afiliados. A partir de 1988 gobierna, entre otras, la ciudad de Sao Paulo, el cinturón industrial del ABCD, el puerto de Santos, Porto Alegre y Vitoria, lo que le ha supuesto un bien llevado proceso de "aprendizaje político", que ha complejizado su propuesta política, convirtiendolo en un protagonista imprescindible del pacto social. Su máximo lider, Luiz Inacio Lula da Silva, disputó con la coalición Frente Brasil Popular (en alianza con el PSB y el PC do B) el segundo turno presidencial, perdiendo por una diferencia del $5 \%$. Estrellas en sus trabajos de articulación política en el Congreso son los diputados José Genuino, Aluicio Mercadante, Jose Dirceu; y el senador E. Suplicy, hoy candidato a la sucesión de Luiza Erundina en la alcaldia de Sao Paulo, cuya gestión desmitificadora del "peligro comunista" le pueden dar grandes réditos electorales.En su I Congreso (diciembre de 1991), se consolidan como hegemónica las corriente "Articulaçao", que concibe la democracia cómo única forma de convivencia social, explicita una condena a la dictadura del proletariado y se evoca la lucha armada exclusivamente en legítima autodefensa de un gobierno popular. El PT viene doblando su bancada en el Congreso en las dos últimas elecciones, observandose un crecimiento nacional homogeneo, que se refleja en distintas encuestas que situan a Lula encabezando la disputa presidencial en el primer turno.

\section{Partido Comunista Brasileño (PCB)}

Fundado en 1922, ha podido salir de la clandestinidad en contadas ocasiones $(1927,1933-35,1945-47)$ hasta ser 
legalizado en 1985. Su actitud legalista, le llevo a actuar dentro del MDB, donde se quedaron muchos de sus militantes. Su máximo lider, Roberto Freire viene manteniendo una victoriosa batalla por la renovación del partido.

\section{Partido Comunista do Brasil (PC do B)}

Nacido de una escisión en 1958, se considera el legítimo heredero del PC fundado en 1922. De linea stalinista que pasaría a ser maoista y posteriormente albanesa, consigue tener 6 diputados en la actual legislatura dada su imbricación en algunos movimientos populares, sobre todo de zonas rurales.

\section{Partido Liberal (PL).}

Organizado en 1985 en torno al diputado federal Alvaro Valle (ex-PDS), tuvo importancia en el proceso constituyente con una bancada de seis diputados, ya que uno de sus diputados, Adolfo Oliveira, último lider de la UDN en 1965 , fué relator adjunto del nuevo texto. De fuerte implantación electoral en la zona sudeste, en la actual legislatura cuenta con 16 diputados.

\section{Partido da Renovaçao Nacional (PRN).}

Creado en 1989, servió de vehículo para la candidatura de Fernando Collor a la Presidencia de la Republica, logrando antes de presentarse a elección alguna una bancada de 20 parlamentarios que le posibilitarian el acceso a los espacios gratuitos de la televisión. El apoyo de la TV Globo fue decisiva en la victoria del PRN, que teniendo el gobierno nacional incrementa su bancada en 25 parlamentrios, sieno derrotado en todas sus candidaturas a cargos ejecutivos.

\section{Partido Democrata Cristiano (PDC). y Social Cristiano (PSC).}

Surgido en 1945 como continuador de la experiencia de la Liga Eleitoral Católica de la decada del 30, creceria lentamente hasta los 50. Hasta el golpe del 64 mantuvo estrechas vinculaciones con la DC europea, desaparecidas en la actualidad. Sufriría en 1986 una pequeña escisión, de donde surgiria el Partido Social Cristiano, que acusan al PDC de haber quedado en manos de los grandes propietarios de la tierra. Ambos sobreviven en reductos electorales diseminados principalmente por Norte-Nordeste.

También tienen representación en el congreso, el Partido das Reformas Sociais (PRS), el Social Trabalhista (PST), el Social Democrático (PSD), el Trabalhista Renovador(PTR) y el da Mobilizaçao Nacional (PMN), pero su importancia regional, o elección via coaligaciones y su política de composición les anula su importancia en términos de su proyección sobre la política nacional.

\section{ANEXO III:}

\section{Evolución de votos nulos y blancos.}

\begin{tabular}{cccc}
\hline AÑOS & $\begin{array}{c}\text { SENADO } \\
\text { FEDERAL }\end{array}$ & $\begin{array}{c}\text { CAMARA } \\
\text { FEDERAL }\end{array}$ & $\begin{array}{c}\text { ASSEMBLEIAS } \\
\text { ESTADUAIS }\end{array}$ \\
\hline 1966 & 21,2 & 21,0 & 18,6 \\
1970 & 27,7 & 30,3 & 26,8 \\
1974 & 15,1 & 21,3 & 18,9 \\
1978 & 18,6 & 20,7 & 19,3 \\
1982 & 13,5 & 15,1 & 16,8 \\
1986 & $(*)$ & $(*)$ & $(*)$ \\
1990 & 35,3 & 43,5 & 39,6 \\
\hline
\end{tabular}

\section{ANEXO IV:}

\section{Composición ideológica y partidaria del Congreso Nacional en 1987, 1990 y 1991.}

\begin{tabular}{l|ccc|ccc}
\hline Partidos & \multicolumn{3}{|c|}{ Camara Federal } & \multicolumn{4}{c}{ Senado } \\
Ideología & 1987 & 1990 & 1991 & 1987 & 1990 & 1991 \\
\hline Izquierda & & & & & & \\
$\quad$ PDT & 24 & 38 & 47 & 2 & 5 & 5 \\
PT & 16 & 17 & 35 & - & - & 1 \\
PC do B & 5 & 6 & 5 & - & - & - \\
PCB & 3 & 3 & 3 & - & - & - \\
PSB & 1 & 8 & 11 & 1 & 2 & 1 \\
TOTAL & 49 & 72 & 101 & 3 & 7 & 7 \\
(\%) & 10 & 14 & 20 & 4 & 9 & 8 \\
\hline
\end{tabular}

Centro

\begin{tabular}{lcccccc} 
PSDB & - & 60 & 37 & - & 12 & 10 \\
PMDB & 261 & 131 & 108 & 45 & 22 & 27 \\
TOTAL & 261 & 191 & 145 & 45 & 34 & 37 \\
\hdashline$(\%)$ & 54 & 39 & 29 & 63 & 45,5 & 46
\end{tabular}

\section{Derecha}

\begin{tabular}{|c|c|c|c|c|c|c|}
\hline PFL & 116 & 90 & 87 & 15 & 13 & 15 \\
\hline РТВ & 18 & 28 & 35 & 1 & 4 & 8 \\
\hline PDS & 32 & 32 & 43 & 5 & 3 & 3 \\
\hline PDC & 5 & 15 & 22 & 1 & 7 & 4 \\
\hline PL & 6 & 13 & 14 & 1 & - & - \\
\hline PRN & - & 31 & 40 & - & 3 & 3 \\
\hline Otros & - & 23 & 16 & 1 & 4 & 4 \\
\hline TOTAL & 177 & 232 & 257 & 24 & 34 & 37 \\
\hline$(\%)$ & 36 & 47 & 51 & 33 & 45,5 & 46 \\
\hline & (1) & (4) & (503) & (72) & (75) & \\
\hline
\end{tabular}




\section{ANEXO V:}

Preferencia en relación al sistema de gobierno entre los miembros del Congreso (1991)

\begin{tabular}{lcccccccccc}
\hline Preferencia $(*)$ & Total & PMDB & PFL & PDT & PDS & PRN & PSDB & PTB & PT & Otros \\
\hline Presidencialismo & 26 & 29 & 34 & 33 & 27 & 40 & - & 42 & 18 & 16 \\
\hline
\end{tabular}

Parlamentarismo, con elección directa del presidente de la República 65

Presidencialismo con elección indirecta del presidente de la

\begin{tabular}{lllllllllll} 
República & 8 & 9 & 9 & 9 & 13 & - & - & 8 & - & 10 \\
\hline Parlamentarismo con monarquía & 1 & 2 & 2 & - & 9 & - & - & - & - & 2 \\
\hline
\end{tabular}

(*) Fueron excluidos los entrevistados que no tenían opinión formada o que revelaban idéntica preferencia por diferentes sistemas de gobierno ( $12 \%$ del total)
Fuente:Anexo I, II y III en Lamounier, B. Depois de Transicao. Ed. Loyola, Sao Paulo. 1991. Anexo V Relatorio Pesquise: $O$ Congreso Nacional e a crise brasileira, IDESP, Sao Paulo, 1991.

\section{RESUMEN}

En este articulo, el autor esboza los rasgos más conflictivos de la institucionalidad política en Brasil. En la actual situación de crisis estructural, los partidos políticos se ven presos de una lógica conservadora del status quo. Sin embargo, existen exepciones (PT y PSDB) que articulan sus esfuerzos renovadores con iniciativas que se dan en la sociedad civil en dirección del pacto social.

\section{ABSTRACT}

In this article, the author reviews the more conflictive features of the Brasilian political institutions. Nowadays, in a position of structural crisis, the political parties are catched into a conservative logical of the status quo. However, there are exceptions (PT and PSDB) that articulate their regenerater efforts whith several iniciatives from civil entities on the way of the social contract. 